\title{
Determination of Trace Amount of Cadmium in Real Water And Baby Food Samples By Microinjection Flame Atomic Absorption Spectrometry After Cloud Point Extraction Using Selective Synthesis Ligand
}

\author{
Farnaz Ansar Khameneh ${ }^{1}$, Majid Baghdadi ${ }^{2 *}$, Zahra Monsef Khoshhesab ${ }^{3}$ \\ ${ }^{1}$ Department of Chemistry, Payame Noor University, I.R of Iran \\ farnaz_ansarkhameneh@yahoo.com \\ ${ }^{2}$ Faculty of Environment, University of Tehran, Tehran, Iran \\ m.baghdadi@ut.ac.ir \\ ${ }^{3}$ Department of Chemistry, Payame Noor University, I.R of Iran \\ Monsef kh@pnu.ac.ir
}

\begin{abstract}
A cloud point extraction procedure was used for preconcentration and determination of trace amount of cadmium ion in real water and baby food samples by microinjection flame atomic absorption spectrometry and with using new synthesis dithiocarbamate ligand. The method is based on cloud point extraction of cadmium using triton X-114 as nonionic surfactant. A certain amount of ligand (Complexing Agent) and surfactant was added to samples and after pH adjustment; the sample was heated in a water bath. A hydrophobic complex was formed between cadmium and [N-(2-phenylethyl) dithiocarbamate] ligand and followed by its extraction into triton X-114 surfactant-rich phase.The surfactant-rich phase was diluted with suitable solvent and was separated with using centrifugation, and then measurements were performed with a micro-injection flame atomic absorption spectrometry. Extraction conditions such as $\mathrm{pH}$, amount of Ligand (Complexing Agent) and Surfactant, equilibrium temperature and time, diluent volume and type were optimized. Also ionic strength effect and limit of interferences were studied. Under the optimum conditions, the limit of detection $(3 \mathrm{Sb} / \mathrm{m})$ of $0.2 \mu \mathrm{g} \mathrm{L}^{-1}$, an enhancement factor of 116 and the relative standard deviation $\left(5 \mu \mathrm{g} \mathrm{L}{ }^{-1}, \mathrm{n}=5\right)$ of $4.5 \%$ were obtained. The calibration curve was linear for the concentration range of 0.5 to $20 \mu \mathrm{g} \mathrm{L}^{-1}$ with correlation coefficient of 0.9992 . The proposed method was applied to determination of cadmium ion in water samples including tap water, mineral water, river water and sea water also baby food samples including infant formula powder (milk-based) and infant cereal Powder (wheat and milk-based).
\end{abstract}

\section{Indexing terms/Keywords}

Cloud Point Extraction; Flame Atomic Absorption Spectrometry (FAAS); Cadmium; Baby Food, Water Samples, Complexing Agent

\section{Academic Discipline And Sub-Disciplines}

Analytical Chemistry

\section{SUBJECT CLASSIFICATION}

Chemistry Subject Classification

\section{TYPE (METHOD/APPROACH)}

Experimental study

\section{Council for Innovative Research}

Peer Review Research Publishing System

Journal: Journal of Advances in Chemistry

Vol. 7, No. 3

editor@cirworld.com

www.cirworld.com, member.cirworld.com 


\section{INTRODUCTION}

Study of water and food pollution by heavy metals has been of great interest. Heavy metals such as cadmium (Cd) can be harmful to human health even in very low concentrations, as well as being highly toxic and non-degradable. International agency for research on cancer (IARC) has classified cadmium and cadmium compounds as carcinogenic to humans $[1,2]$

The health risks of cadmium toxicity on human health appearing in 1950 in japan and then many guidelines and organizations were developed to guide the studies about cadmium effects on human health and environment. U.S poison and disease registry was determined cadmium as one of the sixth toxic substances. [3]

Cadmium is toxic to humans even at low concentrations and cause damage to organs such as the liver, kidneys and lungs. [4] Joint FAO/WHO expert committee on food additives (JECFA) recommended a provisional tolerable monthly intake of $25 \mu \mathrm{g} / \mathrm{Kg}$ of body weight for cadmium. [5] a guideline value (allowable) for cadmium in drinking water was determined $3 \mu \mathrm{g} / \mathrm{L}$ by FAO/WHO (2011) [6] Also allowable value for cadmium in baby food samples was determined $0.003-0.08 \mathrm{mg} / \mathrm{kg}$ by United States Environmental Protection Agency (EPA).[7]

Due to high toxicity of cadmium, a sensitive and accurate analytical method is required for measuring and determination of trace amount of cadmium in the samples.

Flame atomic absorption spectrometry due to low cost, speed and ease-of-use is more considered. [8] However, the detection limit for measurement of low levels of cadmium in samples is not suitable, therefore the preconcentration before measurement with flame atomic absorption spectrometry is necessary. The old methods of separating for example a liquid-liquid extraction are used toxic organic solvents which are dangerous to the environment and humans. [9-11]

In cloud point extraction method, a nonionic surfactant such as triton X-114 used which due to the non-volatile and non-flammable properties has no great risk to the environment. In addition, in this method small amount of surfactant about $10 \mathrm{mg}$ for each sample is used.

Various methods have been used for preconcentration of cadmium, including solid phase extraction [2,12] and in situ solvent formation micro-extraction (ISFME). [13] Cost of materials used in mentioned methods, especially in situ solvent formation micro-extraction is very high. In cloud point extraction method, analysis cost is very low and requires short time. [14-17]

In this work, a new synthesis ligand (complexing agent) is used and due to ligand's structure is anticipated to increase the extraction efficiency of cadmium and also it is expected that ligand, form selective complex with cadmium.

\section{CLOUD POINT EXTRACTION PROCEDURE}

Cloud point extraction is a separation and preconcentration procedure which applied for trace metal determination in different matrices. Low cost, high preconcentration factors, environmental safety and simple procedure are mentioned as its advantages. [18] Cloud point extraction is the process in which the surfactant is added to the aqueous solution which containing the component or components that must be extracted. [19]

Surfactants are usually organic compounds that are amphiphilic, meaning they contain both hydrophobic groups (their tails) and hydrophilic groups (their heads). Therefore, a surfactant contains either a water insoluble (or oil soluble) component and a water soluble component. The tail of most surfactants is consisting of a hydrocarbon chain which can be linear, branch or aromatic. [20,21] Figure 1. is showing two-dimensional image of nonionic surfactant (Triton X-114) micellar assembly in an aqueous solution.

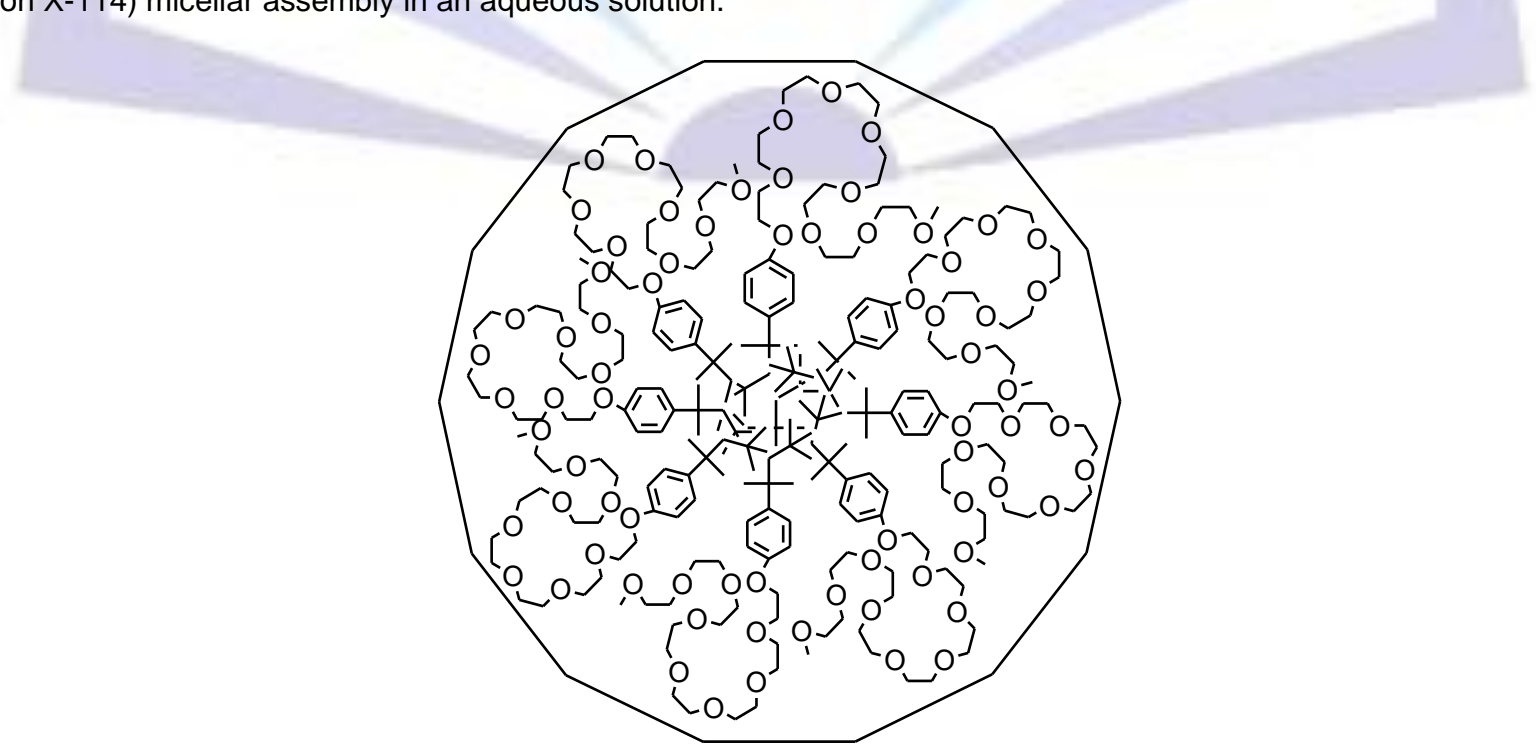

Fig. 1. Two-Dimensional image related to micellar assembly of triton $\mathrm{X}-114$ 
Suitable amount of surfactant shall be added to provide the micelles in the solution. It means that the final concentration of the surfactant shall be exceeding from its CMC (Critical Micelle Concentration). Then for micelle or cloud solution formation, conditions (such as increase or decrease in temperature, increase in salt or other surfactants) are changed and with applying the suitable conditions, surfactant molecules form micelles. In order to speed up the separation of two phases, centrifugation can be used. Finally phase separation is done and a surfactant-rich phase and an aqueous phase will observe. $[19,20]$

The general procedure of cloud point extraction process is shown in Figure 2. as following:
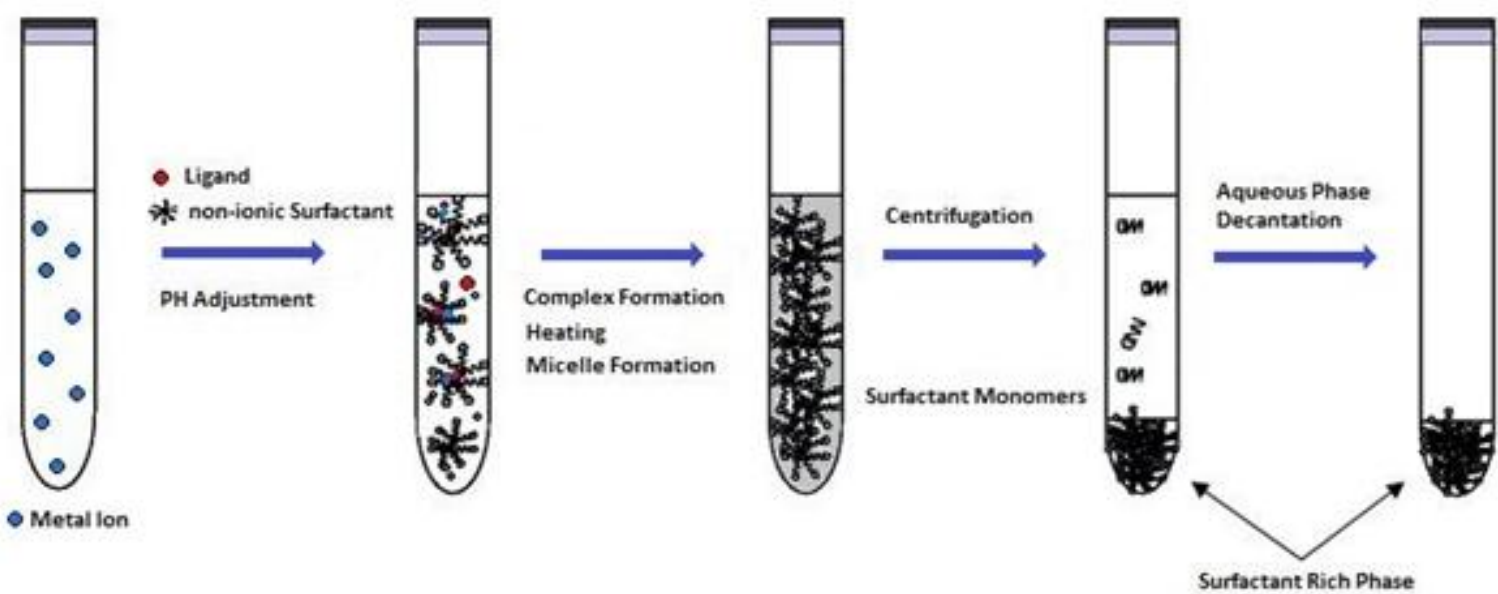

Fig. 2. Cloud point extraction procedure

\section{EXPERIMENTAL}

\subsection{Apparatus}

An atomic absorption spectrophotometer (Varian AA-400) equipped with flame atomization and cadmium hallowcathode lamp was used for determination of cadmium in surfactant rich phase. The operating parameters were set as recommended by the manufacturer. Background correction was carried out using deuterium lamp. A water bath (Fison, model HAKKE-N3) with a good temperature control and a centrifuge with $10 \mathrm{ml}$ calibrated centrifuge tubes (Sanyo Gallenkamp, Model 200,UK) were used to achieve and accelerate the phase separation process. A digital pH meter (Metrohm, Model 691, Swiss) was used to adjust the $\mathrm{pH}$ of all sample solutions.

\subsection{Materials (Preparing Solutions and Standards)}

All chemical materials and reagents were used in analytical grade and purchased from Merck Company except triton X-114 which purchased from Sigma Company. Deionized water was used throughout the experiment. The Stock standard solution of $1000 \mathrm{mg} \mathrm{L}^{-1}$ of cadmium was applied. Working standard solutions were obtained by appropriate dilution of the stock standard solution. Ligand (complexing agent) [ $\mathrm{N}$-(2-phenylethyl) dithiocarbamate] was prepared by adding 1.5 grams of phenylethylamine $\left(\mathrm{C}_{8} \mathrm{H}_{11} \mathrm{~N}\right)$ to $5 \mathrm{ml}$ of carbon disulfide. Then exess of carbon disulfide was evaporated at room temperature with blowing nitrogene gas. Stock ligand solution of $2 \times 10^{-3} \mathrm{~mol} \mathrm{~L}^{-1}$ was prepared by dissolving appropriate amount of ligand in methanol. Complexing agent structure was shown in Figure 3.<smiles>O=C([S-])NCCc1ccccc1</smiles>

Fig. 3. Molecular structure of ligand [N-(2-phenylethyl) dithiocarbamate]

Stock solution of $1 \% \mathrm{w} / \mathrm{v}$ of Triton X-114 (nonionic surfactant) was prepared by dissolving appropriate amount of surfactant in $100 \mathrm{ml}$ distilled water. A buffer solution was prepared by dissolving appropriate amounts of citric acid and sodium citrate in distilled water for obtaining suitable and optimum $\mathrm{pH}$. Stock Standard Solutions $\left(1000 \mathrm{mg} \mathrm{L}^{-1}\right)$ of cations (such as $\mathrm{Cu}, \mathrm{Ni}, \mathrm{Co}, \mathrm{Ca}, \mathrm{Mg}, \mathrm{Mn}, \mathrm{Zn}, \mathrm{Mo}, \mathrm{Pb}, \mathrm{Al}, \mathrm{As}, \mathrm{Fe}, \mathrm{Cr}$ (III \& VI), Hg, V) and anions (such as $\mathrm{SO}_{4}{ }^{2-}, \mathrm{NO}_{3}^{-}, \mathrm{NO}_{2}^{-}, \mathrm{PO}_{4}{ }^{--}$, $\left.\mathrm{Cl}^{-}\right)$were used in interferences studies. All glass containers were placed in $10 \%$ nitric acid solution for 24 hours and before use were washed four times with deionized water. 


\subsection{Sample Preparation}

\subsubsection{Sample Preparation}

For more stability, filtration and acidification of water samples was done and then the samples were kept in dark. Acidification prevents from precipitation of iron hydroxides and other elements that can be absorbed cadmium. Filtration removed colloidal substances and microorganisms which can affect the concentration of cadmium.

Therefore at first, water samples were filtered using $0.45 \mu \mathrm{m}$ pore filter, and then acidified using dilute nitric acid and therefore $\mathrm{pH}$ was set in suitable range (less than 2) and finally, the samples kept in the fridge. [22,23]

The mentioned procedure was applied to tap water, mineral water, river and sea water samples and then ten milliliters portions of the samples were used for testing.

\subsubsection{Preparation of Baby Food Samples (Infant Formula and Infant Cereal Powder)}

For some methods of analysis, it may be required that analytical sample be in a liquid form so, standard procedure to convert solid samples to solutions prior to detection is required.

One of these procedures is digestion. Digestion is the treatment of material with heat, solvents, chemicals, etc., which causes mineralization of the organic constituents of the sample. Wet digestion with oxidizing acids such as $\mathrm{HNO}_{3}, \mathrm{HClO}_{4}$ and hydrogen peroxide is the most common sample preparation procedure. [24-27]

the mentioned procedure was applied to infant formula and infant cereal powder samples. Initially concentrated nitric acid was added to samples, and then the samples were placed on the hot plate with temperature of $120^{\circ} \mathrm{C}$. Nitric acid was added to samples in three stages and in a volume of $5 \mathrm{ml}$ in each stage. Finally $2 \mathrm{ml}$ of perchloric acid was added to samples and heating was continued until the digestion operation is completed also a blank sample was prepared according to the mentioned procedure.

\subsection{Test Procedure}

For the analysis of real samples, two identical volume of sample was considered in which, the spike is the one of the cases.

The Spike samples were analyzed for confirming the accuracy of the method. Therefore, after filtration (for water samples) and digestion (for baby food samples), $10 \mathrm{ml}$ of real samples and also spike samples were prepared and transferred to centrifuge tube.

The water samples were spiked at the level of $15 \mathrm{ppb}$ and the baby food samples at the level of $10 \mathrm{ppb}$. Then optimized amount of buffer, complexing agent and surfactant (Triton X-114) were added to both real and spike samples.

The mentioned samples were shaken and then were placed in a water bath with a temperature of $45^{\circ} \mathrm{C}$ for about 8 minutes, after heating, a cloudy solution was observed.

Separation of two phases was done by centrifugation at $4500 \mathrm{rpm}$ for 8 minutes. Diluting of micellar extracted phase was done by adding $100 \mu \mathrm{l}$ of methanol.

Cadmium was determined by flame atomic absorption spectrometry. Also the solutions with different concentration of cadmium were prepared and used for calibration.

\section{RESULTS AND DISCUSSION}

\subsection{Optimization of Extraction Conditions}

\subsubsection{Effect of Diluent Type and Volume}

Usually, methanol or other organic solvents are used as diluents. Solvents should be able to completely dissolve the surfactant-rich phase. In addition, the solvent should be consistent with detection systems such as flame and plasma. [28] Viscosity of the surfactant-rich phase is effectively reduced by using diluent. The diluent can be able to completely dissolve the surfactant-rich phase and the extracted material. Whatever solvent volume which used for dilution of the surfactant-rich phase be Low, the preconcentration factor and sensitivity will increase . [29] In this work acetonitrile, ethanol and methanol were tested as diluent and finally methanol was chosen as suitable diluent because it has all the characteristics mentioned above. The volume of $100 \mu \mathrm{l}$ of methanol was chosen and used as an optimum amount of diluent in this work. Due to the low sample volume and high volatility of diluent (methanol), the samples should be transferred in plastic-screw-cap containers and the cap is removed before measurement by flame atomic absorption spectrometry. Otherwise, the accuracy and precision of the method will decrease. 


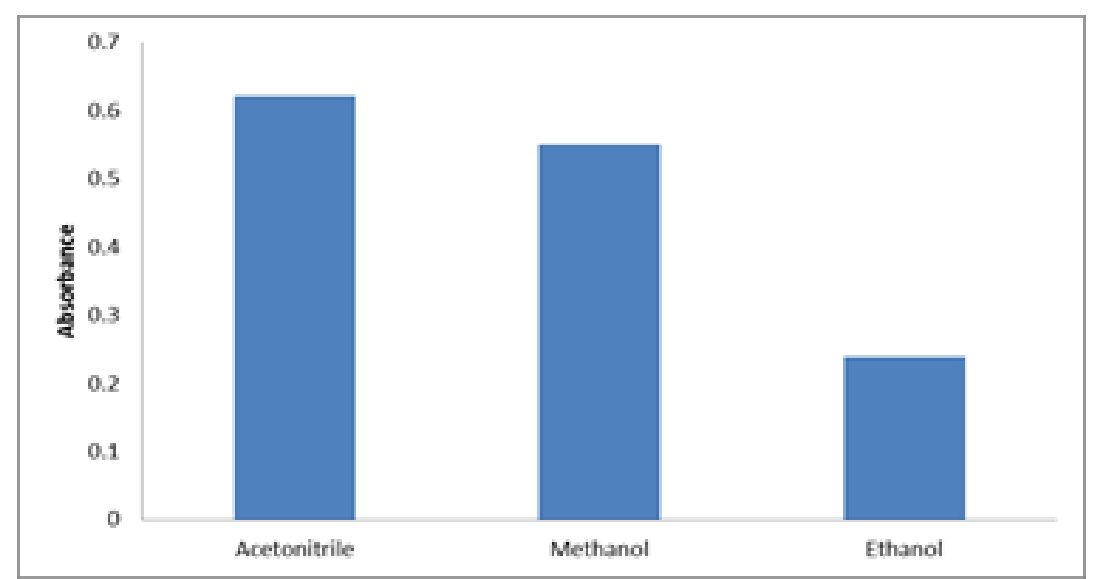

Fig. 4. Diluent selection in cloud point extraction

Conditions: $\mathrm{Cd}\left(20 \mu \mathrm{g} \mathrm{L}^{-1}\right)$, Ligand $2 \times 10^{-3} \mathrm{~mol} \mathrm{~L}^{-1}(120 \mu \mathrm{L})$, Triton X-114 $-1 \% \mathrm{w} / \mathrm{v}(0.7 \mathrm{ml}), \mathrm{pH}=5$, Equilibrium time (8 $\mathrm{min})$, Equilibrium temperature $\left(45^{\circ} \mathrm{C}\right)$

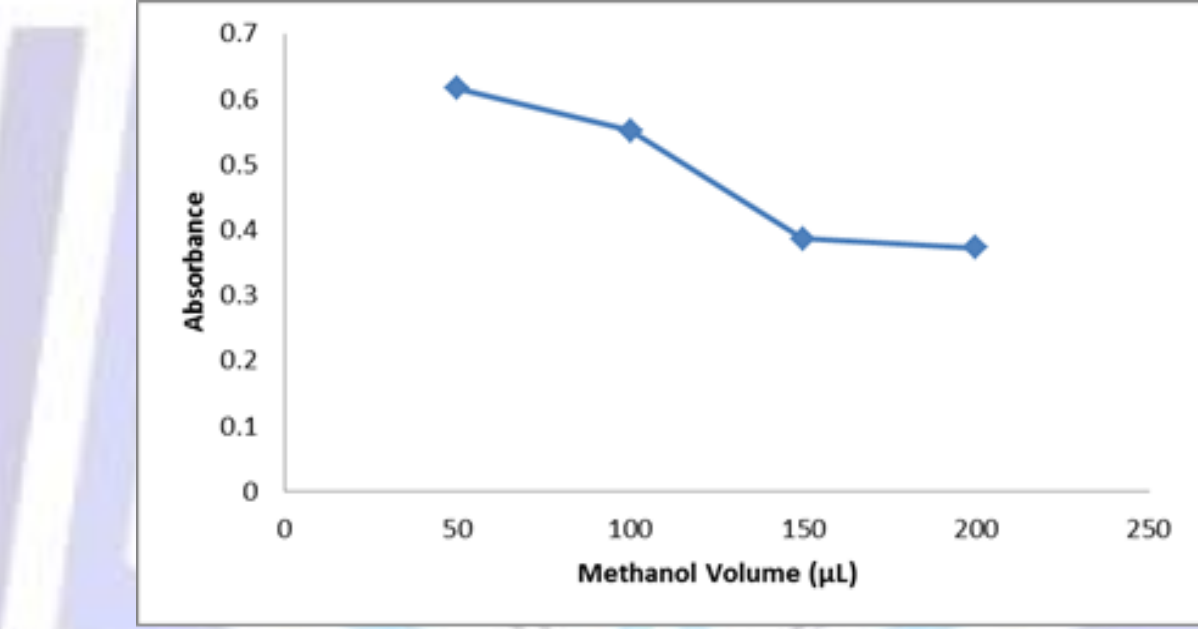

Fig. 5. Effect of diluent (methanol) volume on the cloud point extraction Conditions: $\mathrm{Cd}\left(20 \mu \mathrm{g} \mathrm{L}^{-1}\right)$, Ligand $2 \times 10^{-3} \mathrm{~mol} \mathrm{~L}^{-1}(120 \mu \mathrm{L})$, Triton X-114 -1\% w/v (0.7 ml), pH=5,

Equilibrium time (8 $\mathrm{min})$, Equilibrium temperature (45ㄷ)

\subsubsection{Effect of $\mathrm{pH}$}

A complex with sufficient hydrophobicity is required for separation of metal ions. The mentioned complex can be extracted in a small volume of surfactant-rich phase. The extraction efficiency is dependent on the $\mathrm{pH}$ at which complex formation occurs. Therefore, $\mathrm{pH}$ is the most important parameter affecting the extraction efficiency and it is necessary to choose the optimum $\mathrm{pH}$ at first [30-32]. Cloud point extraction was performed in solutions containing cadmium ion at the $\mathrm{pH}$ range of 1 to 9 . The effect of $\mathrm{pH}$ on the cloud point extraction of cadmium is shown in Figure 6 . The value of $\mathrm{pH} 5.0$ was considered as the optimum $\mathrm{pH}$ for cadmium extraction. 


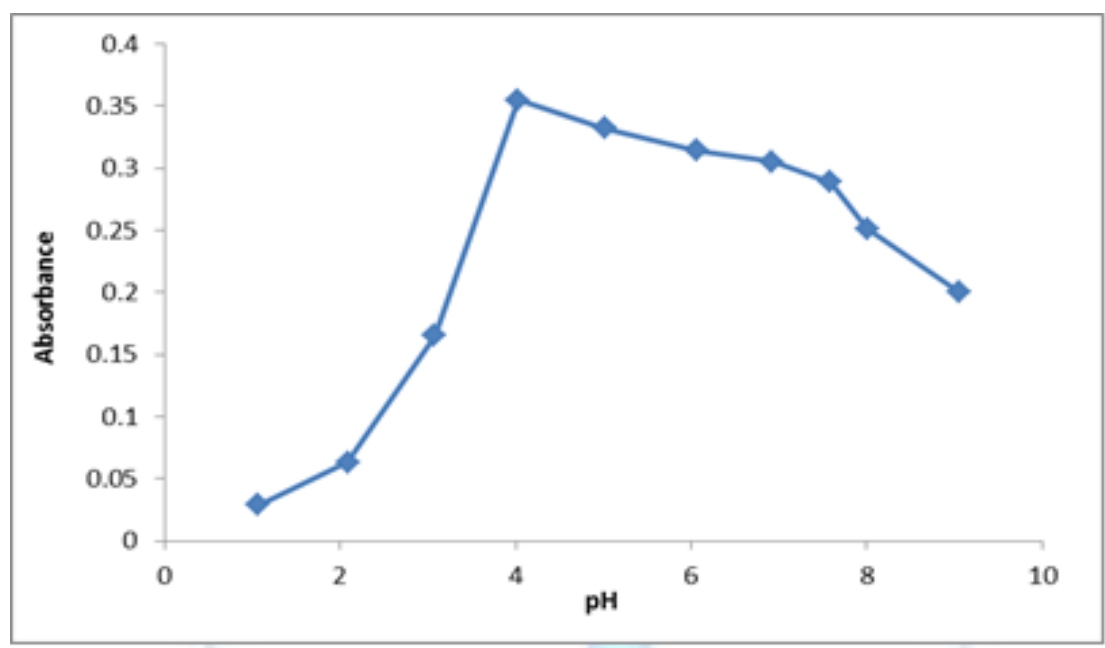

Fig. 6. Effect of $\mathrm{pH}$ on cloud point extraction

Conditions: $\mathrm{Cd}\left(20 \mu \mathrm{g} \mathrm{L}^{-1}\right)$, Ligand $2 \times 10^{-3} \mathrm{~mol} \mathrm{~L}^{-1}(120 \mu \mathrm{L})$, Triton X-114 (1\% w/v, $\left.0.7 \mathrm{ml}\right)$

\subsubsection{Effect of Ligand (Complexing Agent)}

To investigate the effect of complexing agent, $10 \mathrm{ml}$ of solution containing cadmium $\left(20 \mu \mathrm{g} \mathrm{L}^{-1}\right)$ and Triton $\mathrm{X}-114(1 \% \mathrm{w} / \mathrm{v})$ were tested with different volumes of ligand $(0$ to $200 \mu \mathrm{L})$ with concentration of $2 \times 10^{-3} \mathrm{~mol}^{-1}$. The results are shown in Figure 7 . The value of $120 \mu \mathrm{L}$ of $2 \times 10^{-3} \mathrm{~mol} \mathrm{~L}^{-1}$ of ligand was considered as the optimum value.

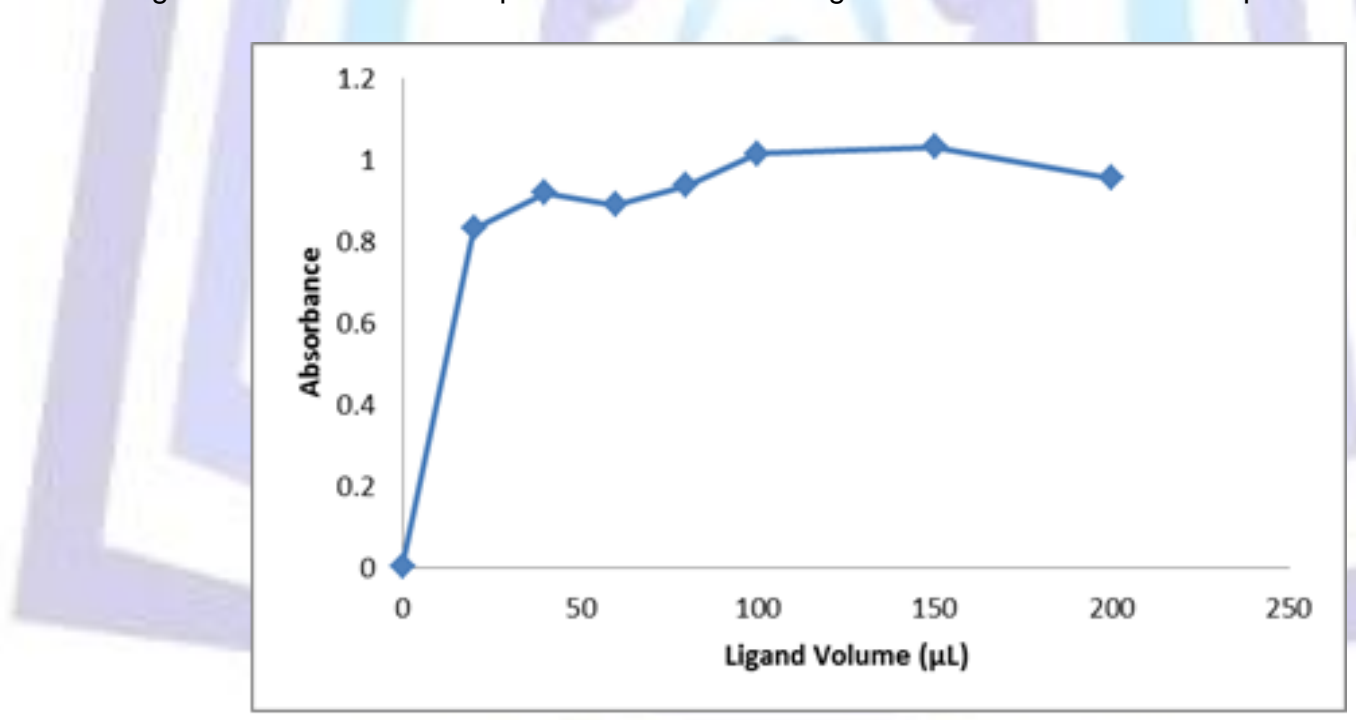

Fig. 7. Effect of ligand (complexing agent) volume on the cloud point extraction Conditions: $\mathrm{Cd}\left(20 \mu \mathrm{g} \mathrm{L}^{-1}\right)$, Triton X-114 (1\% w/v, $\left.0.7 \mathrm{ml}\right), \mathrm{pH}=5$ 


\subsubsection{Effect of Surfactant (Triton X-114)}

Low cloud point temperature and high density of surfactant are two important criteria for selection of suitable surfactant in cloud point extraction. [33,34] Therefore Triton X-114 with low cloud point temperature and high density was chosen as the nonionic surfactant. Also low toxicity, availability and low price of the surfactant were considered for surfactant selection. Different amounts of Triton $(0.1$ to $2 \mathrm{ml})$ were tested and the results are shown in Figure 8.

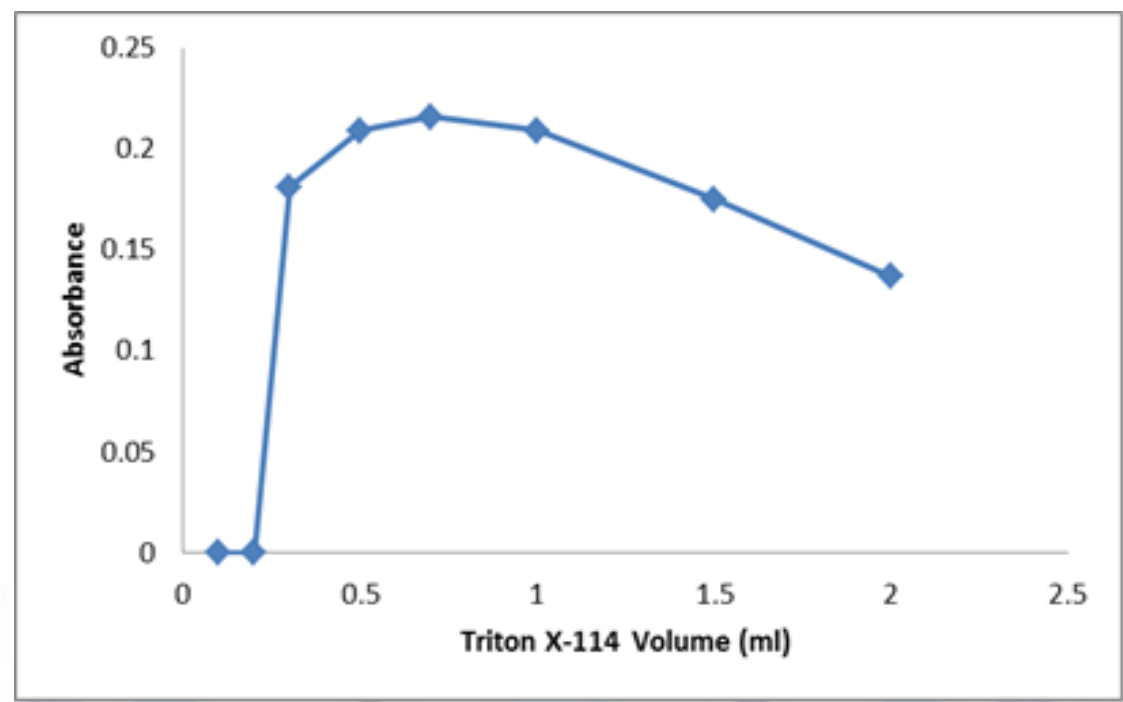

Fig. 8. Effect of triton $\mathrm{X}-114$ volume on cloud point extraction Conditions: $\mathrm{Cd}\left(20 \mu \mathrm{g} \mathrm{L}^{-1}\right)$, Ligand $2 \times 10^{-3} \mathrm{~mol} \mathrm{~L}^{-1}(120 \mu \mathrm{L}), \mathrm{pH}=5$

For improving preconcentration Factor, The phase volume ratio (Vorg/Vaqueous) should be minimized. This will be realized by reducing the surfactant concentration but it should be noted that the surfactant concentration can not be reduced without restriction. On the other hand, as can be seen in Figure.8, with increasing amount of surfactant, the signal intensity decreases. This decreasing does not mean that extraction efficiency is reduced. Due to an increasing in Surfactant-rich phase volume, analyte concentration in the surfactant-rich phase decreases and leading to decrease in analytical sensitivity. [35] Therefore finally the value of $0.7 \mathrm{ml}$ of Triton $\mathrm{X}-114(1 \% \mathrm{w} / \mathrm{v})$, was considered as the optimum amount of surfactant for cadmium extraction.

\subsubsection{Effect of Temperature and Time of Thermal Equilibrium}

With increasing temperature and equilibrium time, surfactant-rich phase volume decreases slightly and this will increase the concentration factor. However, this decrease is not significant and on the other hand, the increase in temperature may lead to decomposition of the complex so the shortest time and lowest equilibrium temperature is selected. [36] Different temperatures $\left(25^{\circ} \mathrm{C}\right.$ to $\left.80^{\circ} \mathrm{C}\right)$ were tested and the results are shown in Figure 9.

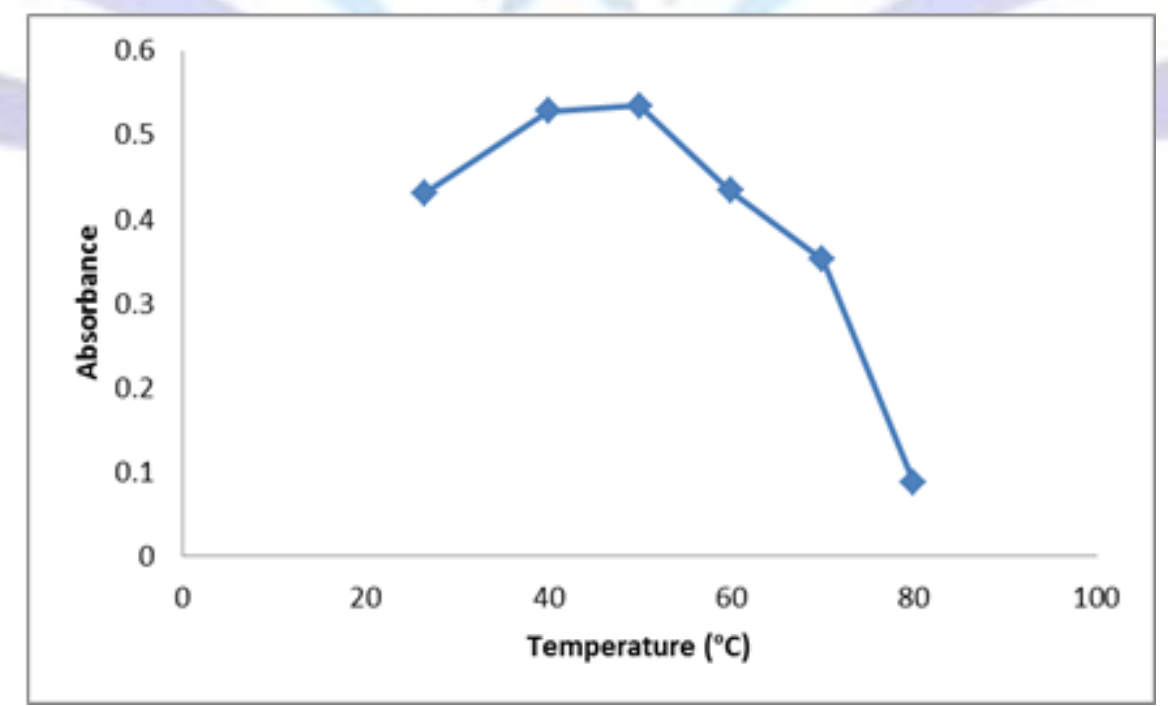

Fig. 9. Effect of temperature on cloud point extraction

Conditions: $\mathrm{Cd}\left(20 \mu \mathrm{g} \mathrm{L}^{-1}\right)$, Ligand $2 \times 10^{-3} \mathrm{~mol} \mathrm{~L}^{-1}(120 \mu \mathrm{L})$, Triton X-114 (1\% w/v, $\left.0.7 \mathrm{ml}\right), \mathrm{pH}=5$ 
As can be seen in Figure 9, the signal intensity is excellent for temperature range from $40^{\circ} \mathrm{C}$ to $50^{\circ} \mathrm{C}$ and decreasing in signal intensity in higher temperatures is observed so finally $45^{\circ} \mathrm{C}$ was considered as the optimum temperature for cadmium extraction. Effect of equilibrium time to signal intensity in the range from 1 to 10 minutes was tested and the time of 8 minutes was chosen as the optimum time. The results are shown in Figure 10.

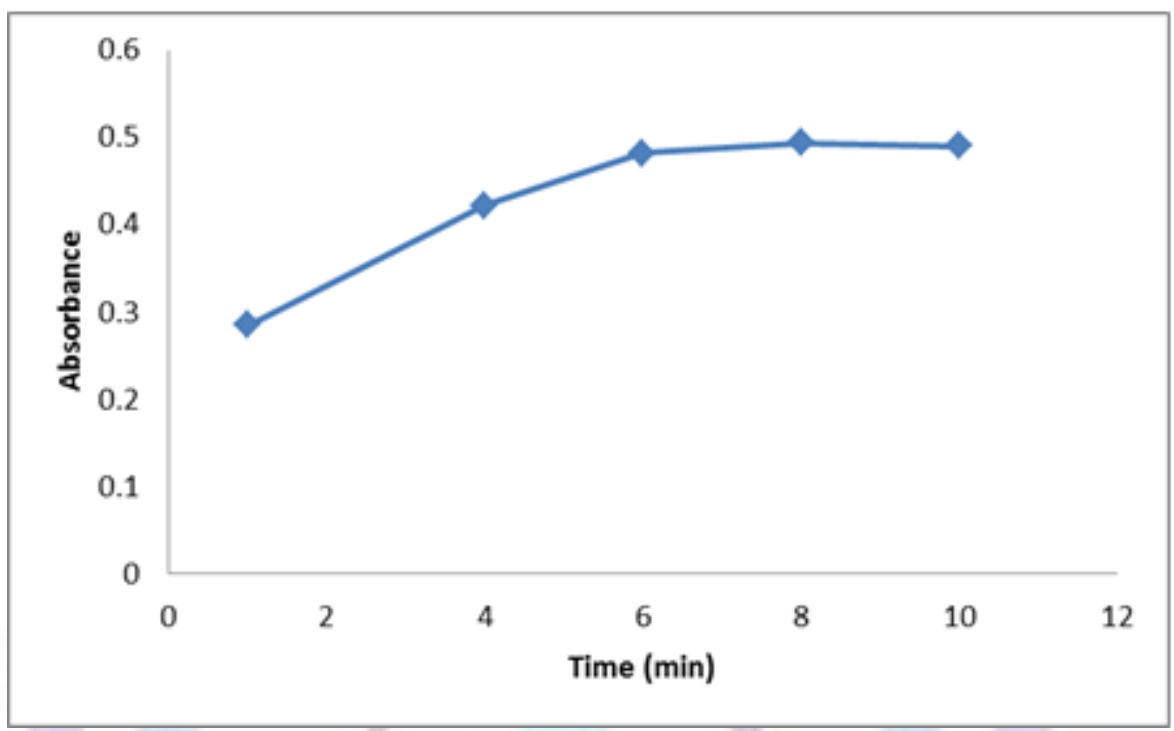

Fig. 10. Effect of time on cloud point extraction

Conditions: $\mathrm{Cd}\left(20 \mu \mathrm{g} \mathrm{L}^{-1}\right)$, Ligand $2 \times 10^{-3} \mathrm{~mol} \mathrm{~L}^{-1}(120 \mu \mathrm{L})$, Triton X-114 (1\% w/v, $\left.0.7 \mathrm{ml}\right)$,

$\mathrm{pH}=5$, Equilibrium Time $(8 \mathrm{~min})$

\subsubsection{Effect of lonic Strength}

lonic strength of the aqueous phase can affect the extraction efficiency by salting out effect. Therefore, influence of the ionic strength on cadmium extraction efficiency and also on the analytical signal was investigated by applying the cloud point extraction procedure to samples by adding different amount of salt. Generally, addition of salt to the micellar solution accelerates phase-separation process. [37,38]

For observing the influence of ionic strength and salting-out effect on cloud point extraction efficiency, various experiments were performed by adding different amount of $\mathrm{NaCl}$ Salt ranging from ( 0 to $1 \% \mathrm{w} / \mathrm{v})$ while the other experimental conditions were kept constant.

It was observed that ionic strength and addition of salt has no significant effect on the cloud point extraction efficiency in this work. Therefore, all the extraction experiments were performed without the addition of salt.

\subsection{Interferences}

Interferences were investigated by a variety of anions and cations by adding the proper ratio of interfering ions to relevant standard solution of cadmium $(10 \mathrm{ml})$ with $20 \mathrm{\mu g} \mathrm{L}^{-1}$ concentration under the optimum conditions.

In this study, interfering ions are the ions which cause significant changes in extraction efficiency more than $5 \%$. There wasn't observed any inappropriate effect of the anions $\left(\mathrm{Cl}^{-}, \mathrm{PO}_{4}{ }^{3-}, \mathrm{SO}_{4}{ }^{2-}, \mathrm{NO}_{3}{ }^{-}\right.$, and $\left.\mathrm{NO}_{2}{ }^{-}\right)$in concentrations in which the interfering ion to analyte ratio was 1000 times.

The results of interferences ions in extraction recovery were shown in Table 1. It can be seen that large excess amounts of common anions and cations don't interfere on determination of trace amount of cadmium.

In the presence of excess ligand, interference of $\mathrm{Hg}^{2+}, \mathrm{Pb}^{2+}, \mathrm{Co}^{2+}, \mathrm{Cr}^{3+}, \mathrm{Cu}^{2+}$ and $\mathrm{V}^{5+}$ was significantly eliminated. 
Table 1. Results Of Interferences lons (Cations and Anions) In Extraction Recovery

\begin{tabular}{|c|c|c|}
\hline $\begin{array}{c}\text { Ion } \\
\text { (Cations and Anions) }\end{array}$ & $\begin{array}{l}\text { Ion/Cd } \\
\text { (w/w) }\end{array}$ & $\begin{array}{c}\text { Cadmium } \\
\text { Extraction Recovery } \\
(\%)\end{array}$ \\
\hline $\mathrm{Ni}^{2+}$ & 1000 & 93.0 \\
\hline $\mathrm{Ca}^{2+}$ & 1000 & 97.2 \\
\hline $\mathrm{Mg}^{2+}$ & 1000 & 99.8 \\
\hline $\mathrm{Mn}^{2+}$ & 1000 & 90.9 \\
\hline $\mathrm{Zn}^{2+}$ & 1000 & 93.7 \\
\hline $\mathrm{Mo}^{6+}$ & 1000 & 91.1 \\
\hline $\mathrm{Al}^{3+}$ & 1000 & 101.9 \\
\hline $\mathrm{As}^{+5}$ & 1000 & 90.7 \\
\hline $\mathrm{Cr}^{3+}$ & 1000 & 92.8 \\
\hline $\mathrm{Cl}^{-}$ & 1000 & 105.8 \\
\hline $\mathrm{PO}_{4}{ }^{3-}$ & 1000 & 98.5 \\
\hline $\mathrm{SO}_{4}{ }^{2-}$ & 1000 & 101.9 \\
\hline $\mathrm{NO}_{3}^{-}$ & 1000 & 106.2 \\
\hline $\mathrm{NO}_{2}^{-}$ & 1000 & 107.9 \\
\hline $\mathrm{Fe}^{3+}$ & 500 & 100.9 \\
\hline $\mathrm{Co}^{2+}$ & 100 & 84.7 \\
\hline $\mathrm{Hg}^{2+}$ & 10 & 93.1 \\
\hline $\mathrm{V}^{5+}$ & 10 & 122.0 \\
\hline $\mathrm{Cr}^{3+}$ & 10 & 105.7 \\
\hline $\mathrm{Pb}^{2+}$ & 10 & 95.9 \\
\hline $\mathrm{Cu}^{2+}$ & 10 & 103.1 \\
\hline
\end{tabular}

\section{ANALYTICAL CHARACTERISTICS OF THE METHOD}

The calibration curve was obtained by preconcentration of $10 \mathrm{ml}$ of sample standard solutions with Triton $\mathrm{X}-114$ under the optimum conditions. Table 2. summarizes the analytical characteristics of the method. Under the optimum experimental conditions, the results indicate that the calibration curve for cadmium was linear from 0.5 to $20 \mu \mathrm{g} \mathrm{L}^{-1}$ with correlation coefficient of 0.9992 . The limit of detection was calculated to be $0.2 \mu \mathrm{g} \mathrm{L}^{-1}$. An enhancement factor of 116 and the relative standard deviation $\left(\mathrm{c}=5 \mu \mathrm{g} \mathrm{L}^{-1}, \mathrm{n}=5\right)$ of $4.5 \%$ was obtained. 
Table 4. Analytical results for cadmium in baby food samples

\begin{tabular}{|c|c|c|c|}
\hline Samples & $\begin{array}{l}\text { Added } \\
\left(\mu g^{-1}\right)\end{array}$ & $\begin{array}{l}\text { Found }\left(\mu g^{-1}\right) \\
\text { Mean+SD }\end{array}$ & Recovery (\%) \\
\hline \multirow{2}{*}{$\begin{array}{l}\text { Infant formula } \\
\text { Powder milk }\end{array}$} & 0 & $0.044 \pm 0.029$ & - \\
\hline & 1.000 & $1.050 \pm 0.021$ & 100.6 \\
\hline \multirow{2}{*}{ Infant Cereal Powder ${ }^{c}$} & 0 & $0.184 \pm 0.022$ & - \\
\hline & 1.000 & $1.235 \pm 0.143$ & 105.1 \\
\hline $\begin{array}{l}\text { a Mean of three experime } \\
b \text { milk-based } \\
c \text { Cerelac (wheat and } r\end{array}$ & standard & & \\
\hline
\end{tabular}

\section{CONCLUSION}

In this work, we proposed a method to determine the trace amount of cadmium using cloud point extraction as an alternative method for the preconcentration of cadmium as a prior step to its determination by flame atomic absorption spectrometry. This method allows the determination of ultra low levels of cadmium by flame atomic absorption spectrometry method which has a less spectral interference than electro thermal method and also requires much less time.

The ligand (complexing agent) presented in this work due to the specific structure which containing the sulfur and benzene ring; have the conditions which is very favorable for the extraction of cadmium.

This method is simple, rapid, sensitive, low cost, and offers good extraction efficiency and has no damaging effect on the environment. Compared with other solvent extraction methods, the method is more secure because it only consumes a small amount of surfactant that has low toxicity.

Compared with other methods, interference with other ions (cations and anions) is minor. This method provides the enhancement factor, detection limit and relative standard deviation as well and in a suitable and acceptable range.

The proposed method can be applied for determination of trace amount of cadmium in water samples such as tap water, mineral water, river water, sea water also baby food samples such as infant formula powder milk and infant Cereal powder.

\section{REFERENCES}

[1] C. Baird,1999, "Environmental Chemistry", 2nd edition, W.H. Freeman and Company, New York.

[2] Yongwen Liu, Xijun Chang, Sui Wang, Yong Guo, Bingjun Din, Shuangming Meng, 2004, "Solid-phase extraction and preconcentration of cadmium(II) in aqueous solution with $\mathrm{Cd}(\mathrm{II})$-imprinted resin (poly-Cd(II)-DAAB-VP) packed columns", journal of Analytica Chimica Acta, volume 519, 173-179.

[3] Jing-Xiu Han, Qi Shang, Yu Du, 2009, "Effect of environmental cadmium pollution on human health" journal of health,Vol.1, No.3,159-166.

[4] Edson Luiz Silva,Paulo dos Santos Roldan, Maria Fernanda Giné, 2009, " Simultaneous preconcentration of copper, zinc, cadmium, and nickel in water samples by cloud point extraction using 4-(2-pyridylazo)-resorcinol and their determination by inductively coupled plasma optic emission spectrometry "Journal of hazardous materials, volume $171,1133-1138$

[5] World Health Organization (WHO) Guidelines for Drinking-water Quality, 2011, Cadmium in drinking water, WHO/SDE/WSH/03.04/80/Rev/1.

[6] World Health Organization (WHO) Guidelines for drinking water quality,2011, fourth edition, ISBN 9789241548151.

[7] John S. Drury and Anna S, Hammons, 1979, "Cadmium in Foods: A Review of the World's Literature", ORNL/EIS149, EPA-560/2-78-007.

[8] Sergio L.C. Ferreira, Jailson B. De Andrade, Maria das Gracas A. Korna, Madson de G. Pereira, Valfredo A. Lemos, Walter N.L. dos Santos, Frederico de Medeiros Rodrigues, Anderson S. Souza, Hadla S. Ferreira , Erik G.P. da 
Silva, 2007 "Review of procedures involving separation and preconcentration for the determination of cadmium using spectrometric techniques" Journal of Hazardous Materials 145, 358-367.

[9] Fabio A.C. Amorim, Sergio L.C. Ferreira, 2005, "Determination of cadmium and lead in table salt by sequential multielement flame atomic absorption spectrometry" Talanta Volume 65, Issue 4, 960-964.

[10] Anthemidis AN, Zachariadis GA, Farastelis CG, Stratis JA, 2004, "on-line liquid-liquid extraction system using a new pHase separator for flame atomic absorption spectrometric determination of ultra-trace cadmium in natural waters" Talanta.62: 437-43.

[11] Carasek, E.; Tonjes, J. W.; Scharf, M, 2002, "A liquid-liquid microextraction system for pb and cd enrichment and determination by flame atomic absorption spectrometry", Quim. Nova, 25, 748-752.

[12] M.Arab Chamjangali, S. Talebzadeh Farooji, B. Bahramian, 2010, "Application of chloromethylated polystyrene functionalized with $\mathrm{N}, \mathrm{N}$-bis (napHthylideneimino) diethylenetriamine in an on-line preconcentration system for the determination of cadmium by FAAS" Journal of hazardous materials, 174, 843-850.

[13] Mahpishanian, S. Shemirani, F, 2010 "Preconcentration procedure using in situ solvent formation microextraction in the presence of ionic liquid for cadmium determination in saline samples by flame atomic absorption spectrometry:, Talanta, 82, 471-476.

[14] Abbas Afkhami, Tayyebeh Madrakian, Hajar Siampour, 2006 ,Flame atomic absorption spectrometric determination of trace quantities of cadmium in water samples after cloud point extraction in Triton X-114 without added chelating agents" Journal of Hazardous Materials B138 , 269-272.

[15] Xiang, Guoqiang; Wen, Shengping; Wu, Xiaoyun; Jiang, Xiuming; He, Lijun; Liu, Yulan., 2012 "Selective cloud point extraction for the determination of cadmium in food samples by flame atomic absorption spectrometry", Food Chemistry, vol.132, 532-536.

[16] Y. Yamini, M. Ghambarian, 2012, "Environmental applications of cloud-point extraction", Reference Module in Chemistry, Molecular Sciences and Chemical Engineering, from Comprehensive Sampling and Sample Preparation Analytical Techniques for Scientists, volume 3, 657-680.

[17] Helen C. Rezende, Clesia C. Nascentes, Nivia M.M. Coelho, 2011, "Cloud point extraction for determination of cadmium in soft drinks by thermospray flame furnace atomic absorption spectrometry", Microchemical Journal, 97,118-121.

[18] Marcos de Almeida Bezerra, Marco Aurelio Zezzi Arruda, Sergio Luis Costa Ferreira, 2005, "Cloud Point Extraction as a Procedure of Separation and preconcentration for Metal Determination Using Spectroanalytical Techniques", Volume 40, Issue 4, 269-299.

[19] Mohammad Reza Jamali, Mohammad Gholinezhad, Saiedeh Balarostaghi, Reyhaneh Rahnama, Seyed Hojjat Allah Rahimi, 2013, "Development of a Cloud-Point Extraction Method for Cobalt Determination in Natural Water Samples" Journal of Chemistry, Volume 2013, Article ID 615175, 7 pages.

[20] Laurier L. Schramm, Elaine N. Stasiuk ,D. Gerrard Marangoni, 2003, "Surfactants and their applications", Annu. Rep. Prog. Chem, Sect. C, 99, 3-48.

[21] Drew Meyers, 2006 , "Surfactant science and technology", Third Edition, John Wiley and sons, Inc.

[22] U. S. Environmental Protection Agency, 1983, "Sample preservation. Methods for chemical Analysis of Water and Wastes", EPA-600/4-79-020 U.S.E.P.A., Cincinnati, Ohio, USA.

[23] U.S. Environmental Protection Agency (EPA), 1994, "Sample Preparation Procedure for Spectrochemical determination of total recoverable elements", Method 200.2, Revision 2.8.

[24] Henryk Matusiewicz, 2003, "New horizons and challenges in environmental analysis and monitoring", Chapter 13 (Wet Digestion Methods), 202-259.

[25] Dr.Heniz Rudel, Dr. Jan Kosters, Diana Homrighausen, Drik Hansknecht, 2011, "Digestion of Environmental Samples, Guidelines for chemical analysis", Fraunhofer Institute for molecular biology and applied ecology.

[26] Maria Balcerzak, 2002, "Sample digestion methods for the determination of trace perecious metals by spectrometric techniques", Analytical Sciences ,vol 18.

[27] Guler somer, Arzu nakisci unlu, 2006, "The effect of acid digestion on the recoveries of trace elements", recommended policies for the elimination of losses", Turk J Chem, $30,745-753$.

[28] ramazan gurkan and nail altunay, 2013, "A reliable method of quantification of trace copper in beverages with and without alcohol by spectropHotometry after cloud point extraction", Quim. Nova, Vol. 36, No. 8, 1146-1154.

[29] Naghi Saadatjou, Shahab Shariati, and Mostafa Golshekan, 2013, "Micelle-Mediated Extraction Prior to LC-UV for Preconcentration and Determination of Trace Amounts of BispHenol A in Environmental Samples", ISRN Analytical Chemistry, Volume 2013, Article ID 357807, 6 pages. 
[30] Morteza Bahram, Somayeh Khezri and Sakineh Khezri, 2013, "Cloud point extraction, preconcentration and spectropHotometric determination of nickel in water samples using dimethylglyoxime", Current Chemistry Letters 2 , 49-56.

[31] celal duran, duygu ozdes, elif celenk kaya, halit kantekin, volkan numan bulut, mehmet tufekci, 2012, "Optimization of a new cloud point extraction procedure for the selective determination of trace amounts of total iron in some environmental samples", Turk J Chem,36, 445 - 456.

[32] willie I. Hinme, 1992, "Cloud point extraction and preconcemtration procedures for organic and related pollutants of state concern”, UNC-WRRI-92-269.

[33] Catalina Bosch Ojeda, Fuensanta Sanchez Rojas, Jose Manuel Cano Pavon, 2010, "Preconcentration of Cadmium in Environmental Samples by Cloud Point Extraction and Determination by FAAS", American Journal of Analytical Chemistry,1,127-134.

[34] Mehrorang Ghaedi, Khodabakhsh Niknam, Ebrahim Niknam and Mustafa Soylak, 2009 , "Application of Cloud Point Extraction for Copper, Nickel, Zinc and Iron Ions in Environmental Samples", Journal of the Chinese Chemical Society, 56, 981-986.

[35] Mohammad Ali Salehi , Saeid Alamdar Milani and Nooshin Rahgozar, 2012, "The Effect of Type and Concentration of Surfactant and Ligand on Uranium (VI) Cloud-Point Extraction (CPE) from Aqueous Solutions", Journal of Chemical and Petroleum Engineering, University of Tehran, Vol. 46, No.2,135-142.

[36] M.Ghaedi, K. Niknam and M. Soylak, 2011,"Cloud point extraction and flame atomic absorption spectrometric determination of lead, cadmium and palladium in some food and biological samples" Pak. J. Anal. Environ. Chem. Vol. 12 , No. 1 \& 2, 42-48.

[37] Hosssein Abdolmohammad-Zadeh and Elnaz Ebrahimzadeh, 2011 , "Ligandless Cloud Point Extraction for Trace Nickel Determination in Water Samples by Flame Atomic Absorption Spectrometry", J. Braz. Chem. Soc., Vol. 22, No. 3, 517-524.

[38] Neda Baghban, Ali Mohammad H. Shabani,, Shayessteh Dadfarnia and Abbas A. Jafari, 2009, "Flame Atomic Absorption Spectrometric Determination of Trace Amounts of Cobalt after Cloud Point Extraction as 2-[(2 Mercaptophenylimino)methyl]phenol Complex", J. Braz. Chem. Soc., Vol. 20, No. 5, 832-838. 